\title{
Differential combinatorial interactions of cis-acting elements recognized by R2R3-MYB, BZIP, and BHLH factors control light-responsive and tissue-specific activation of phenylpropanoid biosynthesis genes
}

\author{
Ulrike Hartmann $^{1}$, Martin Sagasser ${ }^{1,2}$, Frank Mehrtens ${ }^{1,2}$, Ralf Stracke ${ }^{1,2}$ and \\ Bernd Weisshaar ${ }^{1,2, *}$ \\ ${ }^{1}$ Department of Plant Breeding and Yield Physiology, Max-Planck-Institute for Plant Breeding Research, \\ Carl-von-Linné-Weg 10, D-50829 Köln, Germany (*author for correspondence; e-mail bernd.weisshaar@ \\ uni-bielefeld.de); ${ }^{2}$ Current address: Genome Research, Department of Biology, Bielefeld University, D-33594 \\ Bielefeld, Germany
}

Received 16 August 2004; accepted in revised form 29 November 2004

Key words: chalcone synthase, flavonols, light regulatory units, regulatory promoter elements, $\mathrm{R}$ response element, transcription factors

\begin{abstract}
Chalcone synthase (CHS), chalcone flavanone isomerase (CFI), flavanone 3-hydroxylase (F3H) and flavonol synthase (FLS) catalyze successive steps in the biosynthetic pathway leading to the production of flavonols. We show that in Arabidopsis thaliana all four corresponding genes are coordinately expressed in response to light, and are spatially coexpressed in siliques, flowers and leaves. Light regulatory units (LRUs) sufficient for light responsiveness were identified in all four promoters. Each unit consists of two necessary elements, namely a MYB-recognition element (MRE) and an ACGT-containing element (ACE). C1 and Sn, a R2R3-MYB and a BHLH factor, respectively, known to control tissue specific anthocyanin biosynthesis in Z. mays, were together able to activate the AtCHS promoter. This activation of the CHS promoter required an intact $\mathrm{MRE}$ and a newly identified sequence designated $\mathrm{R}$ response element ( $\mathrm{RRE}^{A t C H S}$ ) containing the BHLH factor consensus binding site CANNTG. The RRE was dispensable for light responsiveness, and the ACE was not necessary for activation by $\mathrm{C} 1 / \mathrm{Sn}$. These data suggest that a BHLH and a R2R3-MYB factor cooperate in directing tissue-specific production of flavonoids, while an ACE-binding factor, potentially a BZIP, and a R2R3-MYB factor work together in conferring light responsiveness.
\end{abstract}

Abbreviations: ACE, ACGT-containing element; ACS, ACE-like sequence; BHLH, basic helix-loop-helix; BZIP, basic region/leucine zipper; CFI, chalcone flavanone isomerase; CHS, chalcone synthase; chx, cycloheximide; EMSA, electrophoretic mobility shift assay; F3H, flavanone 3-hydroxylase; FLS, flavonol synthase; LRU, light regulatory unit; MRE, MYB-recognition element; MRS, MRE-like sequence; RRE, $\mathrm{R}$ response element

\section{Introduction}

Flavonoids are secondary metabolites unique to plants comprising a great variety of compounds, including flavonols, anthocyanins and condensed tannins (Winkel-Shirley, 2001). They are involved in a number of processes including flower pigmentation, UV resistance, plant-pathogen interactions 
and pollen fertility (Shirley, 1996; Weisshaar and Jenkins, 1998). Since the accumulation of flavonoids is not required for plant fitness under greenhouse conditions, and because the loss of pigments can easily be detected, many mutants affected in this pathway or its regulation have been generated and investigated (Holton and Cornish, 1995).

The first step in flavonoid biosynthesis is catalyzed by chalcone synthase (CHS). The resulting chalcone $\mathrm{C}-15$ scaffold is subsequently modified by the action of chalcone flavanone isomerase (CFI), flavanone-3 hydroxylase $(\mathrm{F} 3 \mathrm{H})$, and flavonol synthase (FLS) to form flavonols (Figure 1; Forkmann and Martens, 2001). For Arabidopsis thaliana, the genes encoding the enzymes involved in the formation of the flavonol aglycons have been identified (Shirley et al., 1992; Pelletier et al., 1997; Wisman et al., 1998; Schoenbohm et al., 2000). Flavonol glycosides, which are formed from flavonols by the activity of specific glycosyl transferases, together with sinapate esters, function in protecting plants against the damaging effects of UV light (Li et al., 1993; Jin et al., 2000).

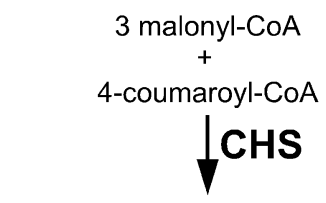

$4,2^{\prime}, 4^{\prime}, 6^{\prime}$ tetrahydroxy-chalcone

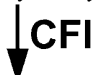

naringenin (flavanone)
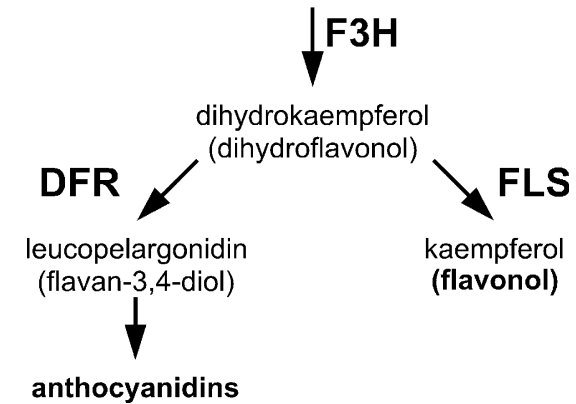

Figure 1. Simplified, schematic representation of the biosynthesis of flavonols and anthocyanidins. The enzymes are indicated in capital letters. Abbreviations are as follows: CHS, chalcone synthase; CFI, chalcone flavanone isomerase (also referred to as $\mathrm{CHI}$ ); $\mathrm{F} 3 \mathrm{H}$, flavanone 3-hydroxylase; FLS, flavonol synthase; DFR, dihydroflavonol 4-reductase. Note that the action of FLS is required for biosynthesis of flavonols while DFR is necessary for biosynthesis of anthocyanidins.
The accumulation of UV-B protective compounds is predominantly controlled at the level of transcription (Chappell and Hahlbrock, 1984; Douglas et al., 1987; Jin et al., 2000), and UV and blue light have been shown to stimulate $C H S$ transcription in several species including $A$. thaliana (Feinbaum et al., 1991; Christie and Jenkins, 1996; Hartmann et al., 1998).

CHS promoters have been studied in great detail (Batschauer et al., 1994), and promoter elements regulating $C H S$ activity in response to UV light are known from mustard (Sinapis alba) and parsley (Petroselinum crispum; Schulze-Lefert et al., 1989; Kaiser et al., 1995). In A. thaliana a light regulatory unit $\left(\mathrm{LRU}^{A t C H S}\right)$, consisting of an ACGT-containing element ( $\mathrm{ACE}^{A t C H S}$ ) and a MYB recognition element ( $\mathrm{MRE}^{A t C H S}$ ), has been identified that is necessary and sufficient to confer light dependent CHS promoter activity (Hartmann et al., 1998). On the basis of the data on cis-acting elements, a number of corresponding DNA-binding proteins have been isolated by biochemical means. Several basic region/leucine zipper (BZIP) factors have been identified which bind to the ACE (Weisshaar et al., 1991; Dröge-Laser et al., 1997). The MRE is recognized by MYB factors containing one or two MYB repeats in the DNA-binding domain (Feldbrügge et al., 1997). It has also been shown that CHS enzyme formation and light dependent $P c C H S$ mRNA accumulation is blocked by cycloheximide (chx) in P. crispum (Hahlbrock and Ragg, 1975; Feldbrügge et al., 1994). The same could be shown for CHS transcription in cultured $A$. thaliana cells under UV-A/ blue and UV-B conditions (Christie and Jenkins, 1996), indicating that the UV light signal transduction cascade involves de novo protein (factor) synthesis (Weisshaar and Jenkins, 1998).

Factors that control transcription of the genes encoding flavonoid biosynthesis enzymes have also been isolated by genetic means (Holton and Cornish, 1995). In Zea mays, the R/Sn-like and $\mathrm{C} 1 / \mathrm{Pl}$-like regulatory proteins control transcription of the anthocyanin biosynthesis genes in different tissues (Mol et al., 1996; Procissi et al., 1997; Mol et al., 1998). R/Sn-like proteins display sequence similarity to the basic helix-loop-helix (BHLH) DNA binding/dimerisation domain along with an acidic domain found in transcriptional activators. The consensus recognition sequence for BHLH proteins is represented by the CANNTG 
motif (Blackwell and Weintraub, 1990; Heim et al., 2003). C1 and Pl are MYB transcription factors of the R2R3-type (Romero et al., 1998; Rabinowicz et al., 1999; Stracke et al., 2001). In $Z$. mays kernels, the presence of both, a R-like BHLH and a C1-like R2R3-MYB factor, is required for transcriptional activation of anthocyanin biosynthesis genes. Pigmentation in floral organs of $Z$. mays is controlled by the transcription factor $\mathrm{P}$ (Grotewold et al., 1994), a R2R3-MYB protein that activates transcription of the $\mathrm{C} 2$ ( $\mathrm{ZmCHS}$ ), $Z m C F I$ and $A 1$ (ZmDFR) genes which are required for both, phlobaphene and anthocyanin biosynthesis. In contrast to $\mathrm{Cl}$ and $\mathrm{Pl}, \mathrm{P}$ does not need a cofactor; it acts alone in activating transcription (Grotewold et al., 1994).

In addition to the data from Z. mays, R2R3MYB and BHLH factors regulating anthocyanin biosynthesis have also been identified by genetic means in Petunia hybrida and Antirrhinum majus. In P. crispum and Nicotiana tabacum, where biochemical approaches were used to define the regulatory proteins involved, MYB and BZIP factors were identified (Weisshaar and Jenkins, 1998). Thus, there is agreement about the involvement of MYB-domain transcription factors in regulating CHS expression, but most genetic data support the involvement of BHLH factors in regulating pigment formation, while most biochemical data support the involvement of BZIP proteins.

In the present study, we describe the coregulation of CHS, CFI, F3H and FLS genes in A. thaliana. Analyses of the $C F I, F 3 H$ and $F L S$ promoters functionally identified the cis-acting elements involved in conferring light responsiveness in all three promoters. These elements are very closely related to $\mathrm{MRE}^{A t C H S}$ and $\mathrm{ACE}^{A t C H S}$, suggesting that the coordinated expression of $C H S, C F I, F 3 H$ and FLS is based on functionally identical ciselements which are recognized by the same factors. In addition, a $\mathrm{R}$ response element (RRE) was identified in the CHS promoter. We demonstrate the differential combinatorial interaction of $\mathrm{MRE}^{A t C H S}$ with either $\mathrm{ACE}^{A t C H S}$ or $\mathrm{RRE}^{A t C H S}$, respectively, in response to different activating stimuli.

\section{Experimental procedures}

Standard molecular biology techniques were applied according to Sambroock et al. (1989). All
DNA sequencing was performed by the MPIZ DNA core facility "ADIS" using BigDye terminator chemistry on Applied Biosystems 377 sequencers. Oligonucleotides were purchased from MWG (Ebersbach, Germany) and Invitrogen (Paisley, GB). DNA fragments were purified using the QIAquick kit ${ }^{\circledR}$ (Qiagen, Hilden, Germany), following the suppliers instructions.

\section{Cell culture and plant material}

A. thaliana plants (Col-0) used for RNA isolation were grown in a greenhouse on soil. Eight-weekold mature plants were dark adapted for $70 \mathrm{~h}$ and then irradiated with UV-containing white light for $3,6,10$ and $24 \mathrm{~h}$ in a phytochamber $\left(40 \mathrm{~W} / \mathrm{m}^{2}\right)$. Plant material was harvested, frozen in liquid nitrogen and stored at $-80{ }^{\circ} \mathrm{C}$ until use. The A. thaliana cell line At7 which grows in the dark has been described previously (Trezzini et al., 1993; Hartmann et al., 1998). To block de novo protein synthesis, protoplasts derived from At7 cells were treated with $10 \mu \mathrm{M}$ cycloheximide; the drug was added to the culture $30 \mathrm{~min}$ before the onset of light irradiation.

\section{$R N A$ isolation and RNA gel-blot analysis}

Isolation of total RNA from plant material and At7 protoplasts was carried out as previously described (Feldbrügge et al., 1994; Hartmann et al., 1998). Ten microgram total RNA was size fractionated in $1 \%$ agarose gels containing formaldehyde, transferred to Hybond-N+ membranes, and hybridized with radiolabelled probes.

\section{Probes for RNA gel-blots and labelling}

Radiolabelled probes were generated by random priming using gel-purified DNA fragments as described previously for the CHS probe (Hartmann et al., 1998). The $F L S$ probe has also been described before (Wisman et al., 1998). The CFI probe was derived from a PCR-fragment corresponding to the CFI cDNA (GenBank accession no. AJ418046). The $F 3 H$ probe was synthesized by RT-PCR using primers oS4 (5'-AGGAACTTTG ACTGAGCTAGCCGGAGAGTC- $3^{\prime}$ ) and oS6 (5'-GACCGTGGTCGCCGAGATTGACGAC 3'). The resulting cDNA fragment covers positions 911 to 1780 in GenBank accession no. U33932 
(Pelletier and Shirley, 1996) excluding the intron. The $U B Q$ probe was a 550 bp EcoRI fragment derived from $A$. thaliana EST clone AttSo348 (accession no. Z17774) encoding polyubiquitin. Conditions for stringent washes were $0.2 \times$ SSC and $0.5 \%$ SDS at $65{ }^{\circ} \mathrm{C}$. X-ray films were exposed at $-80^{\circ} \mathrm{C}$ with intensifying screens.

\section{Promoter isolation and rapid amplification of $c D N A$ ends ( $R A C E$ )}

To isolate the CFI and FLS promoter regions from the accession Columbia-0, a genomic library (EMBL4-gAtCol, kindly provided by Csaba Koncz) was screened. The probe for CFI consisted of $660 \mathrm{bp}$ of the $5^{\prime}$ region of the Landsberg erecta (Ler) CFI gene (Shirley et al., 1992), the $F L S$ probe was the respective cDNA (accession no. U84259). Promoter fragments of $1903 \mathrm{bp}$ (CFI, accession no. AF439537) and 2079 bp ( $F L S$, accession no. U84258) were isolated and sequenced. To isolate the Col-0 F3H promoter, PCR was carried out using genomic DNA and primers oS1 (5'-GCGGGATCCGTTCTCTCAT GG-3') and oS3 (5'-GAGCCATGGTAATTACG AAGACAAAAGAC- $3^{\prime}$ ). Primers were initially designed according to accession no. U33932 which contains the Ler sequence; our Col-0 F3H promoter sequence is available under accession no. AF064064. The transcriptional start sites of the $C F I, F 3 H$ and $F L S$ genes were mapped by Rapid Amplification of cDNA Ends (RACE; Frohman et al., 1988). The initial primer extension reaction was performed using $2 \mu \mathrm{g}$ of total RNA isolated from irradiated At7 cells and primer $1\left(C F I, 5^{\prime}\right.$-ACAGCTTTAGCTTCACAGT C-3'; $F 3 H, 5^{\prime}$-CACTT TCACCCATCCTTCAGG CTTATTTG-3'; $F L S$, 5'-GGAACAAGAAGAG TGATTCCAC-3'). After poly(A) tailing, PCR was performed using primer $2\left(C F I, 5^{\prime}\right.$ TCCATATAGCCACACAA- $3^{\prime} ; \quad F 3 H, \quad 5^{\prime}$-CA CCGGGTACGAGAAATACGTTACAATC- $3^{\prime}$; $F L S, \quad 5^{\prime}$-TAAAGCTAAATCCGGCCGAGG-3') and the SK-T17 primer (Kawalleck et al., 1993). The products were size-separated and analyzed by DNA gel-blot experiments. A second PCR was performed with $2 \mu \mathrm{l}$ of the first PCR reaction as template, the SK primer (Stratagene, Heidelberg) and primer $3\left(C F I, 5^{\prime}\right.$-GACGAATTCACGGAA GAACG-3'; $F 3 H, 5^{\prime}$-CCAATCTTGCACAGCC TCTCC-3'; $F L S, 5^{\prime}$-GAATCCCTAATAACGTC
TCCG- $3^{\prime}$ ). Primer 3 was designed to anneal about $100 \mathrm{bp}$ upstream of primer 2 . The resulting PCR products, which were $100 \mathrm{bp}$ smaller than the hybridizing band, were inserted into pCRscript (Stratagene) and analyzed by sequencing. All primers used for RACE were designed to anneal downstream of the first intron. None of the final sequences obtained for $C F I, F 3 H$ and $F L S$ contained the respective intron.

Promoter deletion and block mutation construction

Promoter constructs for CFI, F3H and FLS promoters were created on the basis of pBT10GUS (Sprenger-Haussels and Weisshaar, 2000) as described before for the CHS promoter (Hartmann et al., 1998). The sequences of the block mutations were as follows: $\mathrm{ACE}^{A t C F I} \mathrm{~m}$, TACcatgGCT (wildtype TACACGTGCT); $\mathrm{MRE}^{A t C F I} \mathrm{~m}$, GC TtctagaCC (wt GCTACCTACCC); MRS2m, Ctc tagaATTG (wt CGTAACTATTG); $\mathrm{ACE}^{A t F 3 H} \mathrm{~m}, \quad$ GCtctagaTT (wt GCCACGTCTT); ACS3m, TTTctagaTT (wt TTTACGTTTT); ACS4m, ATtctagaGC (wt ATCACGTGGC); MRE ${ }^{A t F 3 H} \mathrm{~m}$, GCTAgtcgaCA (wt GCTACCTACCA); MRS3m, ACTAgtcgacG (wt ACTACCTACGG); ACE ${ }^{A t t L S} \mathrm{~m}$, GCCcatgCCT (wt GCCACGTCCT); ACS2m, AACcatgACT (wt AACACGTACT); MRE $^{A t F L S}$ m, GACtctagaCA (wt GACAACTACCA). The LRU ${ }^{A t C F I}$ dimer construct contained two copies of the $61 \mathrm{bp} C F I$ promoter region from -39 to -99 . Double stranded oligonucleotides with compatible BamHI and BgIII restriction sites were ligated into $B a m \mathrm{HI} / B g / I I$-digested pBT10-GUS and dimerised. The FLS promoterbased dimer constructs were created in the same way. The LRU ${ }^{A t F L S}$ construct contained a dimer of the $F L S$ promoter region from -42 to -97 , and the $\mathrm{XU}$ construct the region from -15 to -62 .

\section{Isolation of protoplasts and (co-)transfection experiments}

Protoplast isolation, transfection experiments and illumination conditions for transient expression assays were as described previously (Hartmann et al., 1998), except that $25 \mu \mathrm{g}$ plasmid DNA were used in cotransfection experiments (10 $\mu \mathrm{g}$ reporter plasmid, $5 \mu \mathrm{g}$ effector construct, $5 \mu \mathrm{g}$ standardization plasmid pBT8UBI-LUCm3 (SprengerHaussels and Weisshaar, 2000), and $5 \mu \mathrm{g}$ of a 
promoterless luciferase construct pBT $\Delta$ LUC to end up with a total amount of $25 \mu \mathrm{g}$ DNA). The transfected protoplasts were incubated at $26{ }^{\circ} \mathrm{C}$ for $20 \mathrm{~h}$ in the dark.

Preparation of nuclear extracts and overexpression of $\mathrm{Cl}$

According to a protocol adapted from Green et al. (1987), nuclear extracts for EMSAs were obtained from $40 \mathrm{~g}$ of dark grown At7 cells. Cells were ground to a fine powder under liquid nitrogen. $2.2 \mathrm{vol}(\mathrm{v} / \mathrm{w})$ of nuclei isolation buffer $(20 \mathrm{mM}$ Tris/HCl pH 7.8, $5 \mathrm{mM} \mathrm{KCl}, 5 \mathrm{mM} \mathrm{MgCl}_{2}$, $250 \mathrm{mM}$ sucrose, $70 \%$ (v/v) glycerol, $1 \mathrm{mM}$ DTT, $0.2 \mathrm{mM}$ PMSF) were added and the mixture was gently stirred at $4{ }^{\circ} \mathrm{C}$ until complete suspension of the frozen material. The suspension was consecutively passed through 60 and $20 \mu$ m nylon meshes. The filtrate was centrifuged for $1 \mathrm{~h}$ at $3500 \times g$ at $4{ }^{\circ} \mathrm{C}$. The pellet was gently resuspended in $1.5 \mathrm{vol}$ $(\mathrm{v} / \mathrm{w})$ of nuclei isolation buffer without glycerol and centrifuged as above for $40 \mathrm{~min}$. The nucleicontaining pellet then was resuspended in $0.2 \mathrm{vol}$ of nuclei extraction buffer $(25 \mathrm{mM}$ HEPES/KOH pH 7.8, $50 \mathrm{mM} \mathrm{KCl}, 0.1 \mathrm{mM}$ EDTA, $10 \%$ (v/v) glycerol, $1 \mathrm{mM}$ DTT, $0.1 \%$ 2-mercaptoethanol, $0.2 \mathrm{mM}$ PMSF) and slowly stirred for $30 \mathrm{~min}$ on ice. 0.1 vol. of $4 \mathrm{M}\left(\mathrm{NH}_{4}\right)_{2} \mathrm{SO}_{4}$ were added drop wise under low stirring. After additional stirring for $30 \mathrm{~min}$ on ice, the suspension was centrifuged for $30 \mathrm{~min}$ at $100,000 \times g$. The supernatant was dialyzed against nuclei extraction buffer at $4{ }^{\circ} \mathrm{C}$ and the protein concentration was determined using the BioRad (Munich, Germany) "Protein assay" with BSA as standard.

For overexpression of the $\mathrm{C} 1$ protein the complete ORF (kindly provided by Chiara Tonelli) was PCR amplified using primers oS56 (5'-ATA GGTACCTCCGGAACCATG GGGAGGAGG GCGTGTTGC-3') and oS57 (5'-TATGGATCC ACCGGTCGCAAGCTGCCCGGCCGTCTGAC$\left.3^{\prime}\right)$ to introduce a $N c o$ I-site containing the ATG start codon at the $5^{\prime}$ end and a BamHI site at the $3^{\prime}$ end using a $C l$ cDNA containing plasmid as template. The resulting PCR fragment was cloned into the vector pCRscript (Stratagene). The complete ORF was excised from the vector by cutting completely with BamHI and partially with $N c o$ I (C1 contains an internal $N c o$ I-site). The resulting fragment was ligated into $\mathrm{Nco} /$ /Bam HI-digested
pQE60 (Qiagen) to yield a construct able to express full-length $\mathrm{C} 1$ with a $\mathrm{C}$-terminal (His) ${ }_{6}$ tag $\left(\mathrm{pQE} 60-\mathrm{C} 1:: \mathrm{His}_{6}\right)$. The $\mathrm{C} 1$ protein was isolated from IPTG-induced SG13009 cells (containing pUBS520;Brinkmann et al., 1989) transformed with pQE60-C1::His 6 ; these cells were grown in $100 \mathrm{ml}$ TB medium containing $2 \%$ glucose, $200 \mu \mathrm{g} / \mathrm{ml}$ ampicillin and $25 \mu \mathrm{g} / \mathrm{ml}$ kanamycin to an $\mathrm{OD}_{600}$ of about $0.8 . \mathrm{C} 1:: \mathrm{His}_{6}$ expression was induced by adding IPTG to a final concentration of $2 \mathrm{mM}$ and cells were grown for another $4 \mathrm{~h}$ at $37^{\circ} \mathrm{C}$. Cells were harvested by centrifugation (Heraeus, $4000 \mathrm{rpm}, 10 \mathrm{~min}$ ) and the pellets were frozen at $-80{ }^{\circ} \mathrm{C}$ until further use. Purification of $\mathrm{C} 1:: \mathrm{His}_{6}$ was performed under denaturing conditions on Ni-Agarose columns with subsequent renaturation according to the manufacturers protocol (Qiagen).

\section{Effector constructs for transient cotransfection experiments}

The effector plasmids were derivatives of pBT835S-LUC (Sprenger-Haussels and Weisshaar, 2000) in which the LUC ORF had been replaced. The 35S-C1 construct contains the complete $\mathrm{C} 1$ ORF (see above) ligated into 35S-pBT8 digested with $N c o$ I and BclI. $35 \mathrm{~S}-\mathrm{Sn}$ and $35 \mathrm{~S}-\mathrm{P}$ were constructed in a similar way. The Sn ORF was amplified using the Megaprimer method (Sarkar and Sommer, 1990) using primers oS60 (5'-TATGGATCCACCGGTCCGCTTCCCTAT AG CTTTGCGAAGAG-3'), oS61 (5'-CCGGTC CTCACAATGGACGCCGGCAC- $3^{\prime}$ ) and oS59 (5'-ATAGGTACCTCCGGAACCATGGCGCT TTCAGCTTCCCGAG- $3^{\prime}$ ) to eliminate a $N c o$ I site in the Sn ORF. The P ORF (AF427146) was PCR amplified using primers oUH34 (5'-ATAGGTACC TCCGGAGCCATGGGGAGGACGCCGTGC TGCG-3') and oUH35 (5'-ATAGGATCCACCG GTGATACGCAAGAGCTCCACGC- $3^{\prime}$ ). The PCR templates were plasmids containing the $S n$ and $P$ cDNAs kindly provided by Chiara Tonelli and Erich Grotewold, respectively.

\section{EMSA experiments}

Binding reactions contained in a total volume of $20 \mu \mathrm{l} 1 \times$ binding buffer $(7 \%$ glycerol, $4 \mathrm{mM} \mathrm{KCl}$, $5 \mathrm{mM} \mathrm{MgCl}, 1 \mathrm{mM}$ EDTA, $25 \mathrm{mM}$ HEPES/ $\mathrm{KOH}$ pH7.4), 5 pmoles ${ }^{32} \mathrm{P}$-labeled ACE probe, 
$100 \mathrm{ng}$ unspecific competitor (poly(dIdC)), $2 \mu \mathrm{g}$ nuclear extract protein, and for competition experiments a 5, 25 and 125 molar excess of unlabeled oligonucleotide competitor. The mixture was incubated at room temperature for $10 \mathrm{~min}$. Reactions using $\mathrm{C} 1$ contained $100 \mathrm{ng}$ of purified $\mathrm{C} 1:: \mathrm{His}_{6}$ protein and $1 \mu \mathrm{g} / \mu \mathrm{l}$ of milkpowder (Naturaflor, Töpfer, Dietmannsried, Germany). DNA-protein complexes were separated from unbound probe on $5 \%$ native PAA gels in $0.5 \%$ TBE-buffer (Sambrook et al., 1989) at $15 \mathrm{~V} / \mathrm{cm}$ at $4{ }^{\circ} \mathrm{C}$. After electrophoresis gels were dried and subjected to autoradiography at $-80{ }^{\circ} \mathrm{C}$ with intensifying screens.

\section{Results}

\section{CHS, CFI, F3H and FLS are coordinately} expressed

Flavonol biosynthesis starts from 4-coumaroyl$\mathrm{CoA}$ and malonyl-CoA by the action of the enzymes CHS, CFI, F3H and FLS. Expression of the corresponding genes in various organs of A. thaliana plants was monitored using RNA gel-blot experiments. Transcripts of the four genes were detected in siliques, flowers and leaves (Figure 2A). In general, the relative expression levels were similar. Only transcript accumulation of $C H S$ in siliques and of FLS in flowers were slightly increased compared to the other transcript levels detected.

Pilot experiments demonstrated that dark-adaptation of $A$. thaliana plants for $70 \mathrm{~h}$ resulted in strongly reduced transcript levels of the genes studied. To analyze light induction, plants were dark adapted and transferred to UV-containing white light. Leaf material was harvested at selected time points of constant irradiation. For all four genes tested, transcript accumulation was detectable at $6 \mathrm{~h}$ after the onset of illumination (Figure 2B). Light-dependent expression was also tested in protoplasts suitable for transfection experiments. A. thaliana protoplasts derived from cultured At7 cells were irradiated with UV-containing white light for different time periods. RNA gel-blot analysis demonstrated transcript accumulation $6 \mathrm{~h}$ after onset of light treatment for $C H S$, CFI, F3H and FLS (Figure 2C). The accumulation
(A)

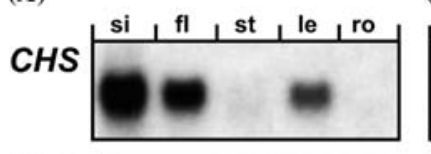

(B)

CFI

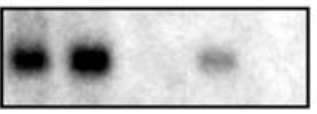

$\mathrm{F} 3 \mathrm{H}$

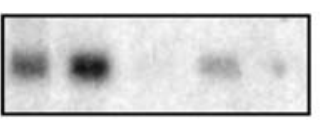

FLS
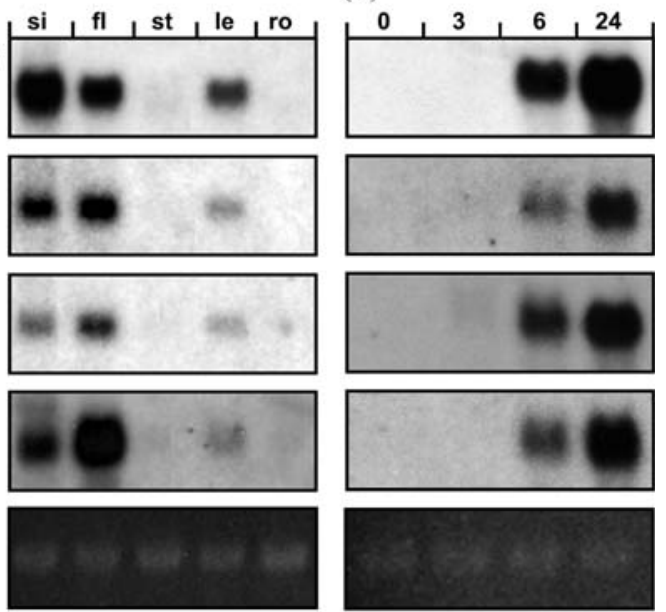

(C)
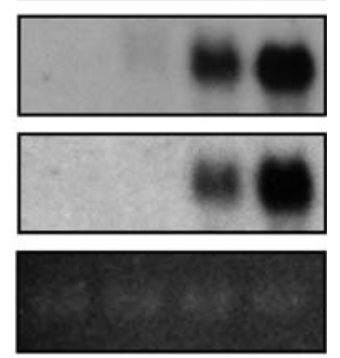

(D)

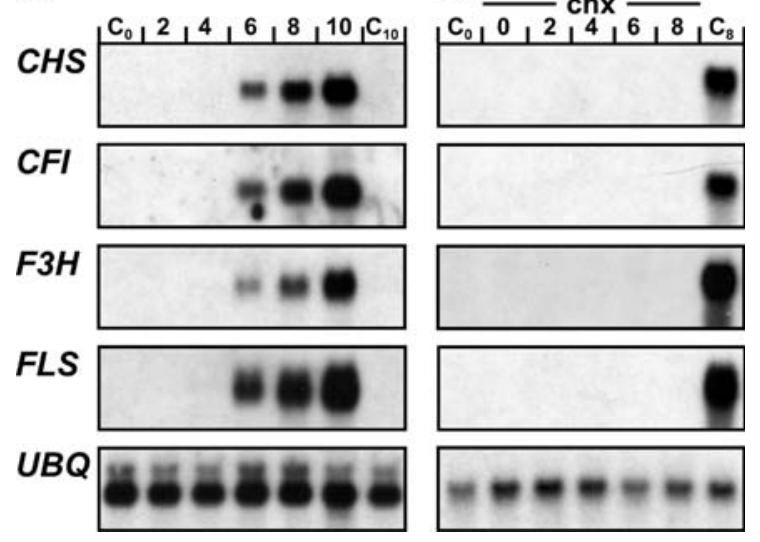

Figure 2. Coordinated accumulation of transcripts of flavonolrelated genes. RNA gel-blot analysis demonstrating coexpression of CHS (At5g13930), CFI (At3g55120), F3H (At3g51240) and FLS (At5g08640) in A. thaliana plants and cultured cells. The same filters were subsequently hybridized with the probes detecting the indicated transcripts. (A) Expression of $C H S, C F I$, $F 3 H$ and $F L S$ in various organs of adult plants. Abbreviations are as follows: si: silique, fl: flower, st: stem, le: leaves, ro: roots. (B) Light-responsive expression of the four flavonol-related genes in leaves of dark-adapted plants. The numbers indicate the time of constant light irradiation in hours. Ethidiumbromide staining of the gels prior to blotting indicates equal loading of RNA (one ribosomal RNA band is shown). (C) Light-responsive expression of the four flavonol-related genes in At7 protoplasts. The numbers indicate the time of constant light irradiation in hours, $\mathrm{C}_{0}$ and $\mathrm{C}_{10}$ indicate controls incubated in darkness. The polyubiqitin $(U B Q)$ probe served as a loading control. (D) Lightresponsive expression of $C H S, C F I, F 3 H$ and $F L S$ is blocked by cycloheximide (chx). Labelling as in (C), except that $\mathrm{C}_{0}$ and $\mathrm{C}_{8}$ indicate controls incubated in the light, not treated with chx.

kinetics for all four transcripts were similar. Taken together, these experiments revealed that $C H S$, $C F I, F 3 H$ and $F L S$ are coexpressed. 
Cylcoheximide blocks the light-dependent $m R N A$ accumulation of $\mathrm{CHS}, \mathrm{CFI}, \mathrm{F} 3 \mathrm{H}$ and $\mathrm{FLS}$

To determine whether de novo synthesis of protein factors is required for the light-dependent accumulation of $C F I, F 3 H$ and $F L S$ transcripts, we used the protein biosynthesis inhibitor cycloheximide (chx). CHS was included as a control. Figure $2 \mathrm{D}$ shows that $C H S, C F I, F 3 H$ and FLS transcript accumulation is blocked by chx. This results suggest that light induced transcription of all four genes requires de novo protein synthesis. Consistently, a lag phase of several hours was observed for gene activation to occur after the onset of illumination (Figure 2C). De novo synthesis of protein factors therefore is an important step in the signal transduction cascade leading to the coordinated activation of all four flavonol biosynthesis genes.

\section{Structure of the A. thaliana CFI, F3H and FLS promoters}

To investigate whether the observed coexpression of $C H S, C F I, F 3 H$ and $F L S$ in response to light is based on a common mechanism, functional elements were identified by transient expression experiments in the $C F I, F 3 H$ and $F L S$ promoters. Since LRU ${ }^{A t C H S}$ has previously been identified in sequences derived from the Col-0 allele of the $\mathrm{CHS}$ gene, we isolated the three other promoter regions also from this accession. The start site of transcription was determined for the $C F I, F 3 H$ and $F L S$ promoters by $5^{\prime}$ rapid amplification of cDNA ends ( $5^{\prime}$ RACE). Figure 3 schematically shows the structure of the promoters of the flavonol-related genes including $C H S$. No additional leader exon which would shift the promoter to a more upstream position was detected in these genes.

For each promoter, $5^{\prime}$-deletion series were assayed by transient expression using At7 protoplasts. All constructs contained the respective promoter-fragment translationally fused to the uidA ORF encoding GUS, and GUS activity was taken as a measure for promoter activity. None of the promoter deletions was active in protoplasts kept in darkness. Deletions to -161 for $C F I,-463$ for $F 3 H$ and -153 for $F L S$, retained high promoter activity in the light and displayed 456-fold, 75-fold and 206-fold light inducibility, respectively

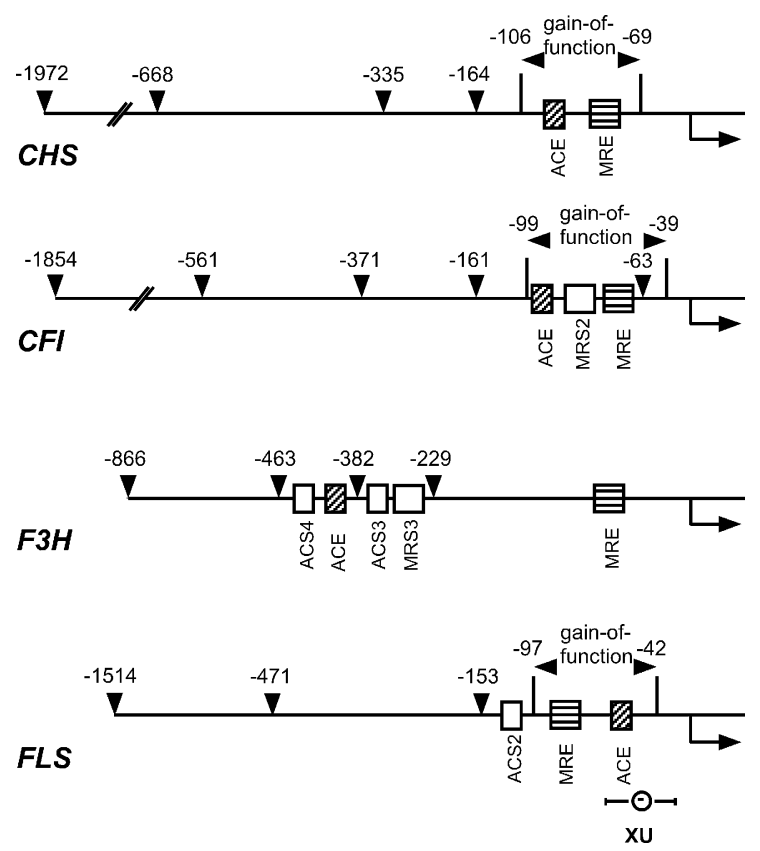

Figure 3. Positions of MYB recognition elements, ACGT containing elements, and related sequences relative to the transcription start site of the A. thaliana CHS, CFI, F3H and $F L S$ promoter. Diagonally and horizontally hatched boxes indicate ACEs and MREs, respectively. Open boxes labelled MRS (MRE-like sequence) and ACS (ACE-like sequence) correspond to promoter regions displaying sequence similarity to MREs and ACEs that were mutated. The bent arrow marks the start site of transcription (referred to as position +1 ) as determined by $5^{\prime}$ RACE. The start sites were located 47,38 , and 46 bp upstream of the ATG start codons for $C F I, F 3 H$ and $F L S$, respectively. Arrowheads mark the $5^{\prime}$ termini of promoter deletions assayed, numbers above the arrowheads indicate the distance to the transcription start site. Arrowheads above the lines mark the borders of the promoter regions which were active in gain-of-function experiments; a non-functional area tested is marked XU below the $F L S$ promoter sketch.

(data not shown). The $-161,-463$ and -153 promoters were operationally defined as the minimal promoters that contain the elements critical for conferring light responsiveness.

Sequence comparison of the $C F I, F 3 H$ and $F L S$ minimal promoters with the light responsive elements of the CHS promoter revealed several potential cis-acting elements similar to $\mathrm{ACE}^{A t C H S}$ and $\mathrm{MRE}^{A t C H S}$ (Figure 3). The CFI promoter contains two potential MYB recognition sequences (MRS), designated MRE ${ }^{A t C F I}$ and MRS2, and one ACGT-containing sequence referred to as $\mathrm{ACE}^{A t C F I}$. The $F 3 H$ promoter contains two putative MRSs (MRE ${ }^{A t F 3 H}$ and MRS3) and three ACS 
motifs, while the FLS minimal promoter sequence displays one MRS and two ACS motifs.

\section{Coactivation of CHS, CFI, F3H and FLS is} conferred by the same type of regulatory unit

To further define the exact cis-acting elements involved in light responsiveness, block mutations were introduced into MRE- and ACE-like sequences in the context of the respective minimal promoters (see Materials and Methods for sequences of block mutations). In the $C F I$ promoter block mutations were introduced in $\mathrm{MRE}^{A t C F I}$, $\mathrm{MRS} 2$ and $\mathrm{ACE}^{A t C F I}$ giving rise to $\mathrm{MREm}$, MRS2m and ACEm, respectively. Mutation of either $\mathrm{MRE}^{A t C F I}$ or $\mathrm{ACE}^{A t C F I}$ (MREm, ACEm) greatly reduced the level of promoter activity in the light compared to the wildtype minimal promoter, whereas a block mutation in MRS2 (MRS2m) only lead to a slight reduction in promoter activity (Figure 4A). These data show that $\mathrm{MRE}^{A t C F I}$ and $\mathrm{ACE}^{A t C F I}$ are necessary for $C F I$ promoter function in response to light. In a gainof-function experiment, the $C F I$ promoter region containing $\mathrm{MRE}^{A t C F I}$ and $\mathrm{ACE}^{A t C F I}$ (designated $\mathrm{LRU}^{A t C F I}$ ) was proven to confer light responsiveness to the heterologous $35 \mathrm{~S}$ core promoter containing

Figure 4. The combination of an ACE and a MRE confers light responsiveness to the $C F I, F 3 H$ and $F L S$ promoters. Bars indicate mean values of GUS' activity (specific GUS activity standardized to the internal luciferase control in each transfection) from six independent transfections with the respective standard deviations. Numbers above the bars indicate promoter activity relative to that of the respective minimal promoter in the light which was set to $100 \%$; below the bar the assayed promoter construct is indicated. Constructs were designated according to the block-mutated sequence element(s). LRU and XU refer to gain-of-function constructs containing the $-4635 \mathrm{~S}$ core promoter and the respective promoter regions described in Figure 3. The horizontal bar on top specifies whether the transfection data in the three panels (A to C) were obtained from protoplasts exposed to light or kept in the dark. Since the activity of all promoter variants was very low, the mean was build over all dark values with a given promoter. (A) Data from constructs based on the -161 minimal CFI promoter. (B) Data from constructs based on the -463 minimal $F 3 H$ promoter. (C) Data from constructs based on the -153 minimal FLS promoter. (D) Sequence comparison of $A$. thaliana $C H S, C F I, F 3 H$ and $F L S$ promoter regions conferring light responsiveness. Nucleotides identical in at least three of the sequences are shaded. Below the sequences nucleotides conserved within the ACEs and the MREs of the various promoters are given. Numbers refer to base positions relative the transcription start site. only a TATA box and initiation site. These results demonstrate that LRU ${ }^{A t C F I}$ is necessary and sufficient to confer light responsiveness.

In the $F 3 H$ promoter, block mutations were introduced in $\mathrm{MRE}^{A t F 3 H}, \mathrm{MRS} 3, \mathrm{ACE}^{A t F 3 H}$, ACS3 and ACS4 giving rise to MREm, MRS3m, ACEm, ACS3m, and ACS4m, respectively. Block mutations in either $\mathrm{MRE}^{A t F 3 H}$ (MREm) or
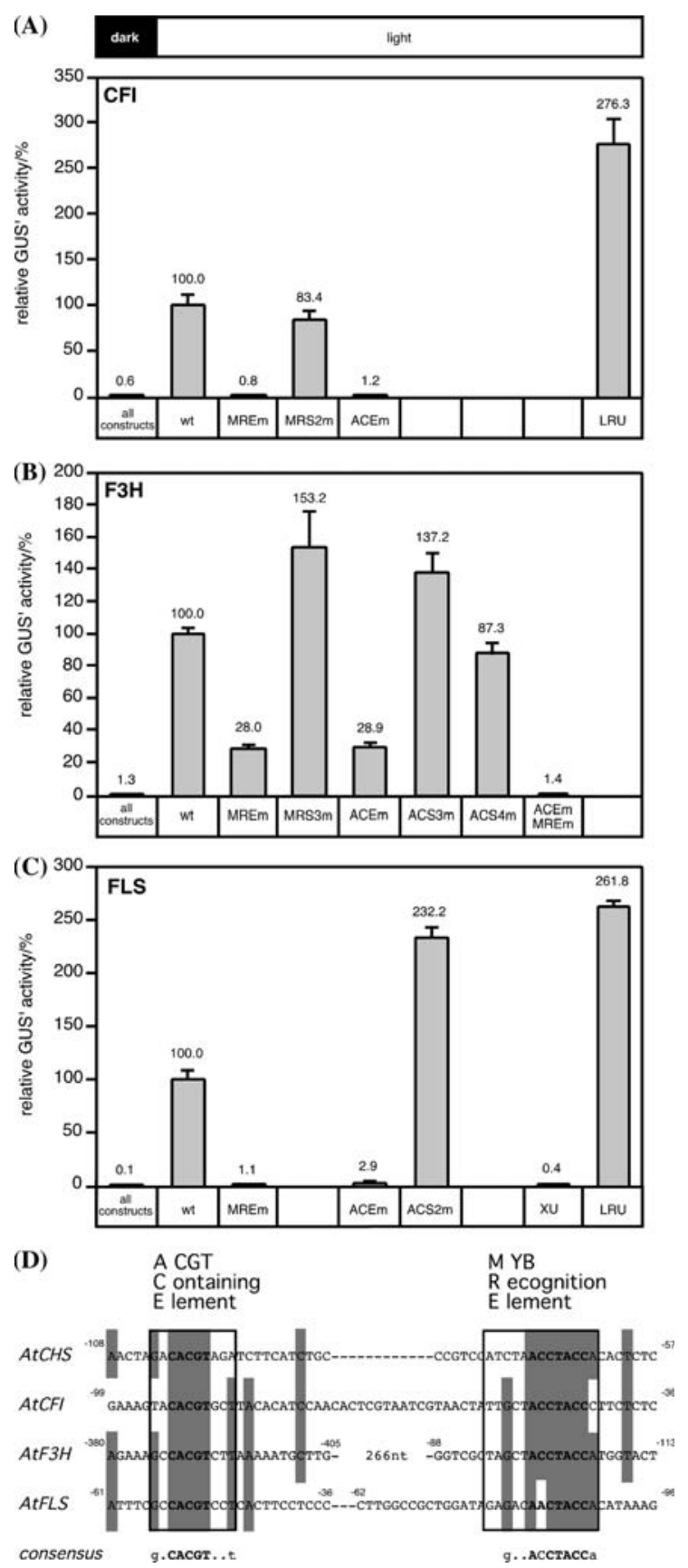
$\mathrm{ACE}^{A t F 3 H}$ (ACEm) lead to a strong reduction to about $28 \%$ of light-dependent promoter activity (Figure 4B). The other mutations only slightly reduced light-dependent promoter activity or even lead to an increase. When the mutations in $\mathrm{ACE}^{A t F 3 H}$ and $\mathrm{MRE}^{A t F 3 H}$ were tested in combination, light responsiveness was lost completely. Since the two elements are separated by about $300 \mathrm{bp}$, no gain-of-function experiment was performed. These data indicate that $\mathrm{ACE}^{A t F 3 H}$ and $\mathrm{MRE}^{A t F 3 H}$ are necessary to confer light responsiveness to the $F 3 H$ promoter.

Also the $F L S$ promoter was analyzed in transient expression assays (Figure 4C). Mutations in either MRE ${ }^{A t F L S}$ or $\mathrm{ACE}^{\text {AtFLS }}$ resulted in a dramatic decrease of promoter activity in the light, whereas a block mutation in ACS2 (ACS2m) lead to a 2.3-fold induction of promoter activity compared to the wildtype minimal promoter, indicating that $\mathrm{MRE}^{A t F L S}$ and $\mathrm{ACE}^{A t F L S}$ are promoter elements necessary to confer light responsiveness. In a gain-of-function experiment LRU ${ }^{A t F L S}$, containing $\mathrm{MRE}^{A t F L S}$ and $\mathrm{ACE}^{A t F L S}$, was proven to confer light responsiveness to the $35 \mathrm{~S}$ core promoter. A similar construct created on the basis of $\mathrm{MRE}^{A t F L S}$ and sequences downstream of this element (designated XU) was inactive. These data demonstrate that LRU ${ }^{A t F L S}$, which contains $\mathrm{MRE}^{A t F L S}$ and $\mathrm{ACE}^{A t F L S}$, is necessary and sufficient for the light-dependent $F L S$ promoter activity.

In all three promoters analyzed, and in the previously analyzed $C H S$ promoter, the functional cis-acting elements conferring light responsiveness are (i) a MYB recognition element (MRE) and (ii) an ACGT-containing element (ACE). Alignment of these functionally relevant sequences revealed a consensus sequence for MRE and ACE, respectively (Figure 4D). The coordinated expression of CHS, CFI, F3H and FLS in response to light is therefore conferred by the combinatorial action of two distinct cis-acting elements which are common to all four promoters.

\section{Similar transcription factors bind to the ACES of the CHS, CFI, F3H and FLS promoters}

Due to the sequence similarity observed and the functional relationship of the ACEs studied, it is likely that these elements are bound by the same class of transcription factors. To test this hypothesis, electrophoretic mobility shift assays
(EMSA) were performed using $A$. thaliana nuclear extracts and double stranded oligonucleotides representing the four distinct functionally characterized ACEs. Two specific DNA-protein complexes typical for BZIP proteins were detected when $\mathrm{ACE}^{A t C H S}$ was used as labelled probe (Figure 5). Formation of these complexes was reduced when increasing amounts of unlabelled $\mathrm{ACE}^{A t C H S}$ competitor DNA were added. This competition was not observed using the respective mutated version $\left(\mathrm{ACEm}^{A t C H S}\right)$. Similar results were obtained when the other ACEs were used as competitors; the wildtype sequences did compete while the mutated versions did not. The slower migrating complex (upper band) did show slightly higher specificity than the faster migrating complex (lower band). When $\mathrm{ACE}^{A t C F I}$ and $\mathrm{ACE}^{A t F L S}$, respectively, were used as labelled probes similar results were obtained (data not shown). Since all ACEs did show a similar pattern of retarded bands and since all ACEs did cross-compete, we conclude that similar factors do recognize all four ACE variants.

\section{The MREs of the CHS, CFI, F3H and FLS promoters are specifically bound by $\mathrm{Cl}$ in vitro}

To determine if the functionally defined MREs of the CHS, CFI, F3H and FLS promoters can be recognized by a R2R3-MYB factor, EMSAs were performed using recombinant $\mathrm{C} 1$ protein. As shown in Figure 6B a specific DNA complex was detected with all four wildtype MREs (lanes 1, 3, $5,7)$, which was not formed when the respective MRE core was mutated (lanes 2, 4, 6, 8). These results demonstrate that the MRE sequences functionally defined by transient expression assays are indeed recognized by a R2R3-type MYB factor.

\section{$P$ activates the CHS promoter via $M R E^{\mathrm{AtCHS}}$}

To further unravel the activity of the elements within $\mathrm{LRU}^{A t C H S}$, we tested the activation potential of known, genetically defined factors involved in regulating flavonol biosynthesis genes on the $C H S$ promoter. Since $\mathrm{P}$ is expected to act independently of other factors, we assayed this factor first. As for the light induction, experiments were carried out in the context of the -164 minimal CHS promoter (Figure 7A). P strongly activated the CHS promoter in transient expression 

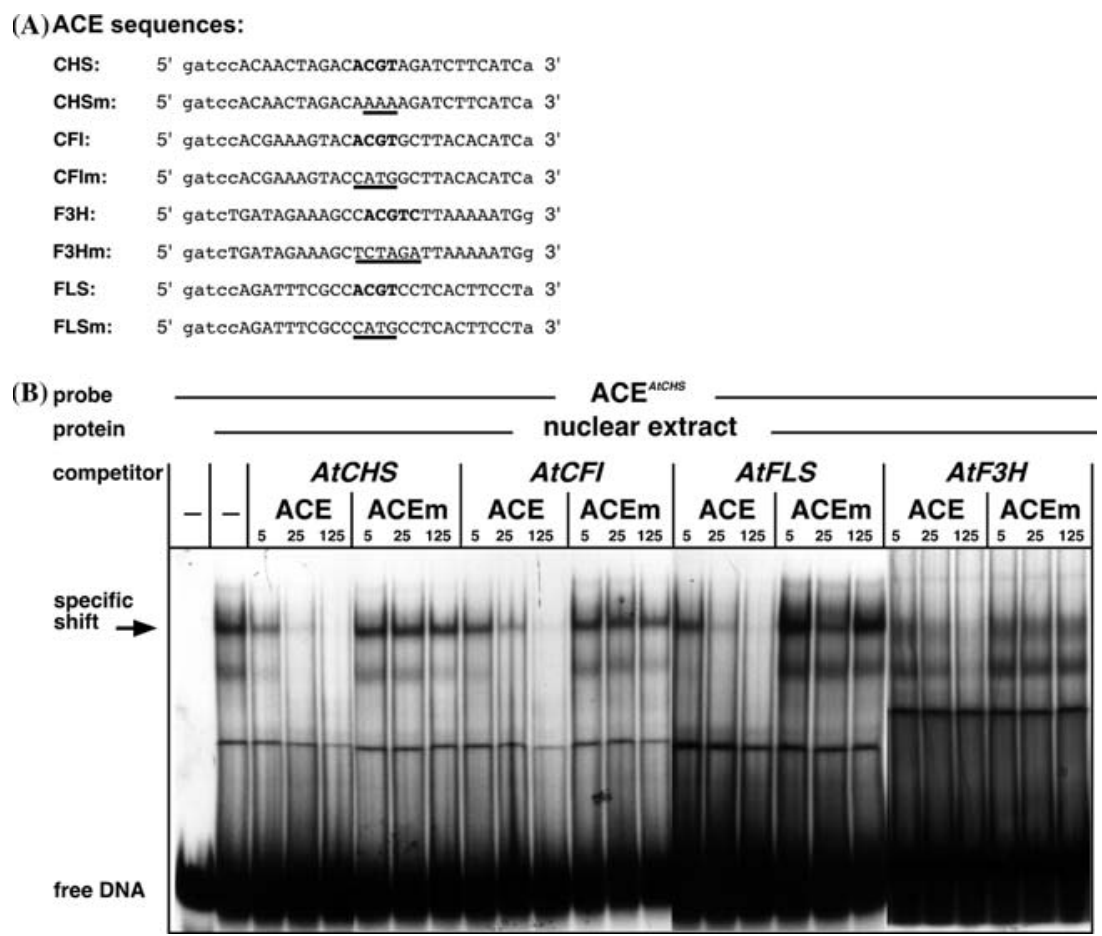

Figure 5. $\mathrm{ACE}^{A t C H S}, \mathrm{ACE}^{A t C F I}, \mathrm{ACE}^{A t F 3 H}$ and $\mathrm{ACE}^{A t F L S}$ are recognized in vitro by the same A. thaliana nuclear factors. (A) Sequences for oligonucleotides used in the EMSA shown in (B). Bold letters highlight ACGT core sequences, mutated positions are underlined. Small characters represent overhangs required for labelling which do not belong to the respective promoter sequence. Only the upper strand sequence is shown. (B) Autoradiograms of EMSAs using A. thaliana nuclear extracts and ACE ${ }^{A t C H S}$ as labelled probe. The unlabelled competitor oligonucleotides included in the binding reactions are indicated. The ratio of competitor to probe was increased in three steps from left to right, the numbers give the fold excess of unlabelled competitor added.

assays (Figure 7B). Mutation of MRE ${ }^{A t C H S}$ completely abolished this activation, suggesting that $\mathrm{MRE}^{A t C H S}$ is a functional binding site for the R2R3-type MYB factor P. None of the other mutations introduced into the $C H S$ promoter (see below) affected activation by $\mathrm{P}$.

\section{$C 1$ and Sn activate the CHS promoter via $a$} $n e w l y$ defined $R$ response element and $M R E^{\mathrm{AtCHS}}$

When $\mathrm{P}$ was replaced by $\mathrm{C} 1$ in the cotransfection assays, no activation was observed (Figure 7C). Likewise, transfections without effector or with Sn alone did not result in activation of the -164 CHS promoter. However, when Sn was combined with $\mathrm{C} 1$, the $C H S$ promoter was strongly activated. A mutation in $\mathrm{MRE}^{A t C H S}$ greatly reduced the level of promoter activity in response to $\mathrm{C} 1$ and $\mathrm{Sn}$, whereas a mutation in $\mathrm{ACE}^{A t C H S}$ had no effect on activation by $\mathrm{C} 1$ and Sn. Mutation of $\mathrm{ACE}^{A t C H S}$ in addition to $\mathrm{MRE}^{A t C H S}$ (MREm and ACEm) resulted in a similar inducibility as the MRE ${ }^{A t C H S}$ single mutant. These results indicate that activation by $\mathrm{C} 1$ plus $\mathrm{Sn}$ was dependent on $\mathrm{MRE}^{A t C H S}$.

We reasoned that the BHLH factor Sn might also, at least in part, act via a cis-acting element. Close inspection of the $C H S$ promoter sequence revealed a candidate target sequence for BHLH factors (Figure 7A). Since the BHLH factor R from $Z$. mays can be considered to be the prototype plant BHLH transcription factor, we designated the element $\mathrm{RRE}^{A t C H S}(\mathrm{R}$ response element). A block mutation in $\mathrm{RRE}^{A t C H S}$ resulted in a strong reduction of promoter activity in response to $\mathrm{C} 1$ and $\mathrm{Sn}$. In addition, simultaneous mutation of $\mathrm{MRE}^{A t C H S}$ and $\mathrm{RRE}^{A t C H S}$ reduced promoter activity even further than either single mutation (Figure 7C). These results demonstrate that $\mathrm{MRE}^{A t C H S}$ and $\mathrm{RRE}^{A t C H S}$ act synergistically to confer $C H S$ promoter activation in response to $\mathrm{C} 1$ and $\mathrm{Sn}$. 
(A) MRE sequences:

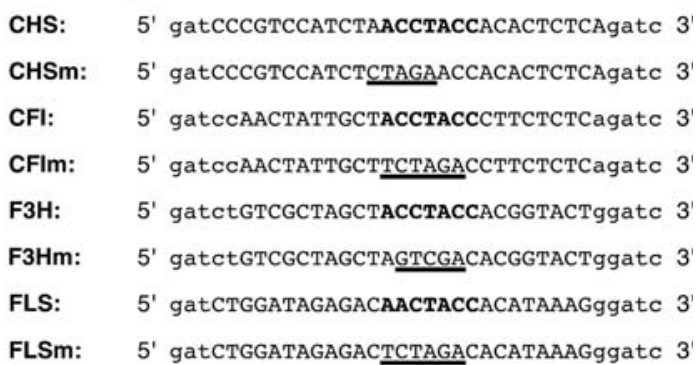

(B) protein:

C1

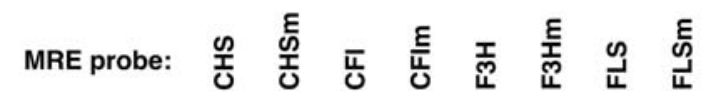

free DNA

lane:

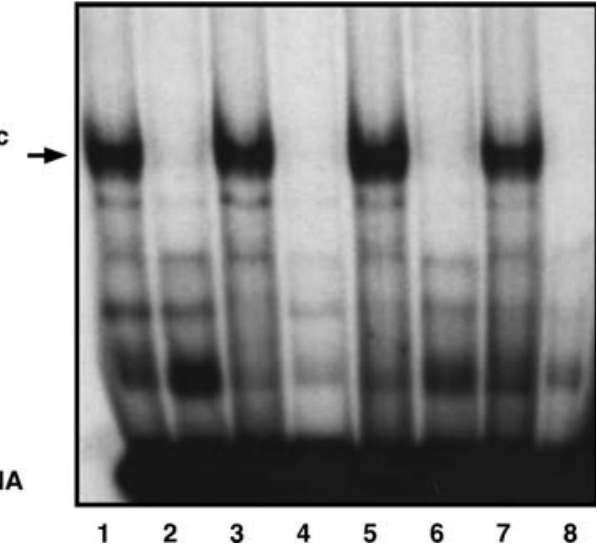

Figure 6. $\mathrm{MRE}^{A t C H S}, \mathrm{MRE}^{A t C F I}, \mathrm{MRE}^{A t F 3 H}$ and $\mathrm{MRE}^{\text {AtFLS }}$ are recognized in vitro by the R2R3-type MYB factor $\mathrm{C} 1$. (A) Sequences for oligonucleotides used in the EMSA shown in (B), the other symbols are as in Figure 5A. (B) Autoradiogram of an EMSA using recombinant $\mathrm{Cl}$ protein and all four functional MRE's as well as the mutant variants as labelled probe. Other symbols are as in Figure 5B.

Figure 7. Separation of cis-acting elements required for light-responsive $C H S$ promoter activity and for transactivation of the CHS promoter by $\mathrm{Cl}$ and $\mathrm{Sn}$ as well as by $\mathrm{P}$. (A) Schematic map of the CHS minimal promoter construct. The rectangle labelled GUS represents the uidA ORF. Diagonally and horizontally hatched boxes indicate $\mathrm{ACE}^{A t C H S}$ and $\mathrm{MRE}^{A t C H S}$, respectively. $\mathrm{RRE}^{A t C H S}$ is represented by a grey box. The bent arrow marks the transcription start site. Below the map, the relevant nucleotide sequences of the wildtype promoter (wt) and of the block mutation constructs are presented. Bold letters highlight core consensus sequences of the various elements, small characters indicate mutated positions in the wildtype context which is represented by dashes. (B-D) Results of transient expression assays on the activation of the AtCHS promoter by factors provided in trans or by light. The constructs shown in (A) are compared to each other in relation to the wildtype promoter the activity of which was set to $100 \%$. Numbers on top of the bars indicate relative activity in percent. The respective reporter construct and effector factor(s) or stimulus applied are indicated below the bar diagrams.
Mutations in $R R E^{\mathrm{AtCHS}}$ and $A C E^{\mathrm{AtCHS}}$ separate the responses of the CHS promoter to light and to $\mathrm{Cl} / \mathrm{Sn}$

The newly identified functional $\mathrm{RRE}^{A t C H S}$ was assayed in the context of the previously characterized mutations with regard to light responsiveness
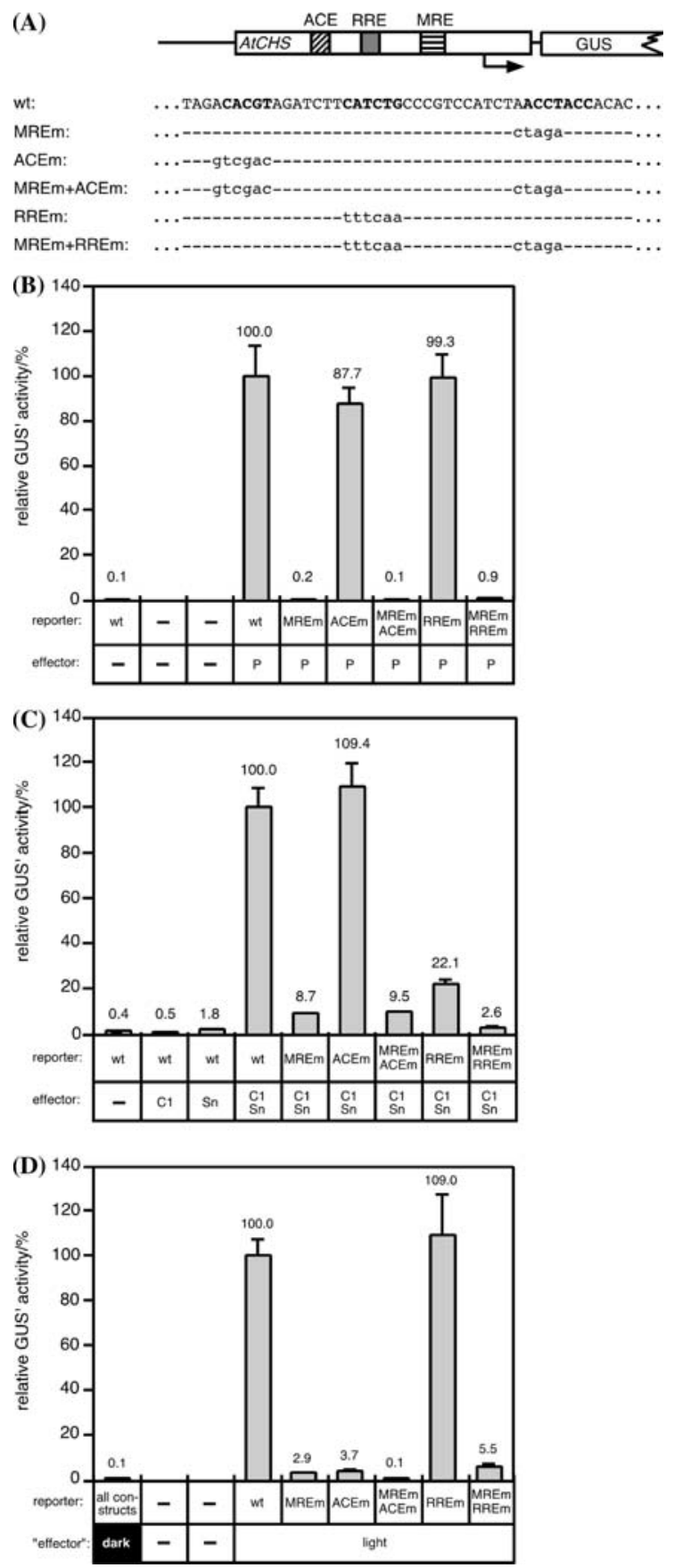
(Figure 7D). Mutation of MRE ${ }^{A t C H S}$ affected light responsiveness as described before, but the mutation of $\mathrm{RRE}^{A t C H S}$ which reduces activation by $\mathrm{Cl}$ / Sn by $80 \%$ had no effect on the light responsiveness. The opposite was true for a mutation of $\mathrm{ACE}^{A t C H S}$ which had no effect on activation by $\mathrm{Cl}$ / Sn but which abolishes light responsiveness.

In summary, our results showed that in each case the activation of the CHS promoter by light, $\mathrm{C} 1 / \mathrm{Sn}$ and by $\mathrm{P}$ is dependent on MRE ${ }^{A t C H S}$. While the light-dependent promoter activity also relies on $\mathrm{ACE}^{A t C H S}$, the promoter activity in response to $\mathrm{C} 1$ and $\mathrm{Sn}$ depends on $\mathrm{RRE}^{A t C H S}$. These data show that differential interactions of $\mathrm{MRE}^{A t C H S}$ with other cis-acting elements are crucial in generating the complex expression pattern of the $C H S$ gene.

\section{Discussion}

Coordinated expression of $\mathrm{CHS}, \mathrm{CFI}, \mathrm{F} 3 \mathrm{H}$ and FLS

RNA gel-blot experiments showed that the flavonoid biosynthesis genes $C H S, C F I, F 3 H$ and $F L S$ are expressed in A.thaliana leaves, flowers and siliques. These organs have been shown to be the main sites of flavonol accumulation in adult A.thaliana plants (Koornneef et al., 1982; Li et al., 1993; Shirley et al., 1995). Dark-adaptation of plants resulted in very low levels of $C H S, C F I, F 3 H$ and $F L S$ transcripts. In leaves of dark-adapted adult plants as well as in At7 protoplasts, a strong light-dependent accumulation of the four transcripts was detected, with similar accumulation kinetics for all four analyzed transcripts. These observations fit well to the assumed role of flavonols in protection against UV, where they are thought to play a crucial role together with sinapate esters (Jin et al., 2000). It should be noted that the dark adaptation failed to suppress transcript accumulation when the plants are stressed (by stresses other than light). This effect can become visible if the stress is so strong that parts of the plants turn purple due to anthocyanin accumulation, a process that requires the activity of $C H S, C F I$ and $F 3 H$.

The plants used for RNA extraction were grown under conditions that do not cause anthocyanin accumulation. In the organs tested, either all four or none of the flavonoid biosynthesis gene transcripts were detected. This observation is in good agreement with the fact that the activities of all four gene products are required for flavonol formation and are probably organized in a multienzyme complex as indicated by yeast-two-hybrid experiments and colocalization studies (Winkel-Shirley, 2001). However, small differences in the expression levels were observed. These differences in transcript levels might not necessarily result in different protein levels. They possibly reflect the need for different activities in the very complex flavonoid biosynthesis pathway, where some activities are necessary for the production of many (in case of CHS for all) kinds of flavonoids, whereas others are only needed for one subclass of flavonoids (like FLS for flavonols).

Different subclasses of flavonoids are synthesized in response to different stimuli, in different organs and at different developmental stages. For the synthesis of each flavonoid subclass, coactivation of a different set of genes is required to finally allow synthesis of a given flavonoid. One example is the synthesis of either anthocyanidins or flavonols, which requires (in addition to other functions) DFR activity in case of anthocyanidins and the activity of FLS in case of flavonols (see Figure 1). Another example is the activation of the $B A N Y U L S(B A N)$ gene which leads to the accumulation of catechins, the precursors of the condensed tannin pigments of $A$. thaliana seeds. A lack of BAN activity results in seeds that accumulate anthocyanins (Nesi et al., 2000, 2001).

The transcript accumulation kinetics of $\mathrm{CHS}$, CFI, F3H and FLS after UV-light treatment showed a lag phase of about $6 \mathrm{~h}$ before a parallel increase in transcript level for all four genes was detected (Figure 2B and 2C). Similar results were obtained for leaves from dark-adapted mature plants and protoplasts from dark-grown At7 cells, again demonstrating that the cell culture represents a suitable test system (Hartmann et al., 1998). The observed lag phase may be explained by the need for de novo protein factor synthesis during the light signal transduction process, an interpretation that is consistent with the block of transcript accumulation by the protein biosynthesis inhibitor chx (Figure 2D). The block of protein synthesis by chx affects expression of all four genes in a similar way, an observation that extends earlier results on A. thaliana CHS (Christie and Jenkins, 1996). 
The presence of flavonols has been described in roots of developing seedlings and is discussed in the context of auxin signaling (Murphy et al., 2000; Buer and Muday, 2004; Peer et al., 2004). We did not detect $C H S, C F I, F 3 H$ or $F L S$ transcripts in RNA from soil-grown adult roots. This finding might indicate that transcript levels in roots are below the detection limits of RNA gel-blots, that possibly root tips were missed by harvesting from soil, or, more likely, that the presence of flavonols in roots is dependent on the developmental stage with low or undetectable transcript levels of the respective genes in adult roots. These developmentdependent changes are also in accordance with the results presented by Peer $e t$ al. (2001), who reported decreasing levels of flavonol aglycones in the course of $A$. thaliana seedling development. Data on transcript accumulation for the phenylpropanoid biosynthesis genes PAL1,CHS,CFI and DFR in response to light were also obtained from 3-day-old A. thaliana seedlings (Kubasek et al., 1992). In such young seedlings, $P A L 1$ mRNA began to accumulate before $C H S$ and $C F I$ mRNAs, which, in turn, both started to accumulate before $D F R$ mRNA, reflecting the order of steps in flavonoid biosynthesis. In these studies a much reduced lag phase and expression levels reaching a maximum as early as 2.5 hours after the onset of illumination were reported (Kubasek et al., 1992; Pelletier and Shirley, 1996). These findings indicate that the control of flavonoid biosynthesis gene expression in seedlings might be different from the control in adult plants that were addressed in this study. In fact, it has been shown that in seedlings $C H S$ gene expression is under control of the phytochrome system while in adult tissues it is controlled by the cryptochrome system (Kaiser et al., 1995). We assume that this developmental switch affects the other genes of the pathway in a similar manner. Taken together, our data revealed that the four enzymes catalyzing flavonol biosynthesis are coexpressed with respect to organ and developmental stage specificity as well as in response to light, and that de novo protein synthesis is needed for light-dependent accumulation of their transcripts.

Structure and function of the A. thaliana CFI, $\mathrm{F} 3 \mathrm{H}$ and $\mathrm{FLS}$ promoters

The parallels in transcript accumulation observed for all four genes under investigation suggested a common regulatory mechanism. It is known that the regulation of $C H S$ expression occurs mainly on the level of transcription (Chappell and Hahlbrock, 1984; Dangl et al., 1987; Feinbaum and Ausubel, 1988; Weisshaar et al., 1991). The CHS promoter is one of the best studied plant promoters and several elements necessary and sufficient to control light induction of $C H S$ expression have been identified (Weisshaar and Jenkins, 1998). These promoter elements are conserved among $C H S$ genes of various plant species (Hartmann et al., 1998; Koch et al., 2001). The light regulatory unit (LRU ${ }^{A t C H S}$ ) of the A. thaliana Col-0 allele of $C H S$ was characterized in detail and was shown to contain the functional cis-acting elements $\mathrm{ACE}^{A t C H S}$ and MRE $^{A t C H S}$ (Hartmann et al., 1998). In the present study, we show that the same control elements also occur in the promoters of the three other coexpressed flavonol biosynthesis genes (Figure 3). In all four promoters, light responsiveness was conferred by one ACE and one MRE. It should be noted that mutation of a single element strongly reduces promoter activity, but only double mutations abolish light inducibility completely. Each element therefore confers a basal light responsiveness, but only their combination yields the full response that is more than the sum of the responses conferred by the single elements. So, in all identified light regulatory units, ACE and MRE act synergistically to confer light responsiveness.

In any case, functional assays were required to identify the active element among several candidate sequences that could not be distinguished by sequence information alone. This observation highlights a general problem of in silico promoter analyses. It has been shown that sequences flanking the ACGT core motif influence the binding specificity of BZIP proteins (Williams et al., 1992; Izawa et al., 1993). The sequences shown to be non-functional in our assay may not be recognized by the factor(s) involved in light induction. However, this does not exclude their participation in promoter activation processes in response to other stimuli or in other surroundings. Alternatively or in addition, the spacing of the cis-elements in the promoters might be relevant, as demonstrated for the parsley CHS promoter (Block et al., 1990). The relative positioning of cis-elements might either allow or prevent a productive interaction of factors that need to contact each other for successful promoter activation. 
When compared to the CHS promoter, both functional cis-elements in the $F 3 H$ promoter occur in reverse orientation. In the $F L S$ promoter, only the MRE shows reverse orientation, and it is the only case in which the MRE is located upstream of the ACE. Among the genes analyzed, the $F 3 H$ promoter appears to be most divergent with respect to the presence of a clear TATA box like element (that is missing in all the others) and the much wider spacing of the elements in relation to the transcription start site. Most probably, these differences are compensated by protein interactions that are taking place in three dimensions and which allow the cooperation of the regulatory factors at each of the four promoters. On the other hand, the promoter differences might also reflect altered regulation under conditions not related to light induction. Hints for such altered regulations come from $A$. majus, where $F 3 H$ is coregulated with $D F R$ during flower development and not with $C H S$ and CFI (Martin et al., 1991; Jackson et al., 1992).

The observation that the mutation of ACS3 and MRS3 in the F3H and ACS2 in the FLS promoter lead to increased reporter activity (Figure 4) raises the possibility that these sequence elements are the binding sites for negative regulators of the light response. Jin et al. (2000) found that the transcription factor $A t \mathrm{MYB} 4$ acts as a repressor of $\mathrm{C} 4 \mathrm{H}$, a gene involved in hydroxycinnamic acid metabolism. Upon wounding or UVtreatment $\mathrm{C4H}$ is derepressed, resulting in increased synthesis of protective sinapate esters. This demonstrates that derepression mechanisms are involved in activating phenylpropanoid biosynthesis genes in response to UV light. Therefore, prevention of repressor binding to the mutated cis-acting elements might account for the observed increased promoter activities.

Differential interaction of MRE binding factors with factors recognising either the RRE or the ACE

All ACEs tested showed a similar pattern of retarded bands when incubated with nuclear extracts and all ACEs were able to cross-compete these complexes. This observation correlates the ability of a nucleotide sequence to confer light responsiveness with its capacity to be bound by nuclear proteins and indicates that all four ACE variants are recognized by similar factors. Most ACGT binding factors known so far belong to the class of BZIP proteins, suggesting that the shifted bands detected in the EMSA experiments result from binding of BZIP factors to the probes. ACE sequences closely related those assayed here were also found to be bound in vitro by CPRF and GBF BZIP factors (Armstrong et al., 1992; Schindler et al., 1992). However, it should be noted that in vitro data do not prove that the ACE-binding activity in vivo is also a BZIP factor. Only the ACE from the $C F I$ promoter shows flanking sequences giving rise to a symmetrical G-box (Foster et al., 1994; Menkens et al., 1995) that also fits the consensus of the R motif (CANNTG; Blackwell and Weintraub, 1990; Bodeau and Walbot, 1996) which is recognized by BHLH factors. It might be that $\mathrm{ACE}^{A t C F I}$ serves a dual role in stimulus- and tissue-specific gene regulation.

MYB factors have been shown previously to bind MRE-like sequences and to be involved in regulation of flavonoid biosynthesis in various species. For example, the flower specific factors $A m \mathrm{MYB} 305$ and $A m \mathrm{MYB} 340$ both interact in a sequence-specific manner with the P-box of the CFI promoter from A. majus (Moyano et al., 1996); and for Z. mays C1 sequence-specific DNA binding to the promoter of the $A l$ gene was shown (Sainz et al., 1997). The activation of the CHS minimal promoter by $\mathrm{Cl} / \mathrm{Sn}$ is mediated via a MRE and a newly defined R-recognition element (RRE), acting synergistically and independently of a functional ACE. Similarly, in several Z. mays promoters (e.g. BRONZE2; Bodeau and Walbot, 1996) a "C1-motif" and a "R-motif" have been identified which are important for coactivation by specific MYB and BHLH transcription factors. Analysis of the Phaseolus vulgaris CHS15 promoter indicated that a $39 \mathrm{bp}$ region, containing G-box and H-box elements, directed both, tissuespecific expression (Faktor et al., 1997b) and stress-responsive activation (Faktor et al., 1997a) in transgenic tobacco plants. The H-box shares similarity with the C1-motif and may act as a MRE. In Z. mays the MYB factor P controls the formation of 3-deoxy-flavonoids and phlobaphenes. In contrast to $\mathrm{P}, \mathrm{C} 1$ is involved in the control of anthocyanin biosynthesis and activates anthocyanin biosynthesis genes only in combination with a BHLH cofactor. These findings clearly illustrate that different branches of the flavonoid pathway are differentially controlled by distinct 
MYB factors, and that these factors work via different modes of action. These different modes may either include combinatorial interactions of a given MYB factor with other transcription factors, more or less independent gene activation by the MYB factor in question, or even repression as reported for AtMYB4 (Jin et al., 2000).

Genetic analysis in Z. mays, P. hybrida and A. majus has focused on tissue-specific and developmental regulation of pigment formation, whereas in biochemical systems like P. crispum, $N$. tabacum and $A$. thaliana stimulus-dependent expression, in particular the response to light or fungal elicitors, has been studied. The discrepancy between the identification of BHLH factors in Z. mays, P. hybrida and A. majus and BZIP factors in P. crispum, $N$. tabacum and A. thaliana could be explained on the basis of the results reported here. We hypothesize that BZIP factors may act predominantly in stimulus-dependent gene activation, while BHLH factors mainly serve to activate genes in a cell-identity dependent manner, at least in the context of flavonoid biosynthesis gene activation. Members from both factor families may share the ability to interact with MYB factors in generating specificity by combinatorial action.

\section{Acknowledgements}

We thank Ute Tartler for excellent technical assistance, and Klaus Hahlbrock and Imre E. Somssich for helpful discussions and continuous support throughout the project. We are grateful to Chiara Tonelli for providing the cDNAs encoding $\mathrm{ZmCl}$ and $Z m S n$, to Erich Grotewold for providing the cDNA encoding $Z m \mathrm{P}$, and to Csaba Koncz for providing the $A$. thaliana genomic library. This work was supported in part by EC-BIOTECH Grant No. BIO2 CT93 0101 to B.W., by the DFG (Deutsche Forschungsgemeinschaft) and also by the Max-Planck-Society.

\section{References}

Armstrong, G.A., Weisshaar, B. and Hahlbrock, K. 1992. Homodimeric and heterodimeric leucine zipper proteins and nuclear factors from parsley recognize diverse promoter elements with ACGT cores. Plant Cell 4: 525-537.

Batschauer, A., Gilmartin, P.M., Nagy, F. and Schäfer, E. 1994. The molecular biology of photoregulated genes. In: R.E. Kendrick, G.H.M. Kronenberg, (Eds.), Photomorpho- genesis in Plants, 2nd edn. Kluwer Academic Publishers, Dordrecht, The Netherlands, pp. 559-599.

Blackwell, T.K. and Weintraub, H. 1990. Differences and similarities in DNA-binding preferences of MyoD and E2A protein complexes revealed by binding site selection. Science 250: 1104-1110.

Block, A., Dangl, J.L., Hahlbrock, K. and Schulze-Lefert, P. 1990. Functional borders, genetic fine structure, and distance requirements of cis elements mediating light responsiveness of the parsley chalcone synthase promoter. Proc. Natl. Acad. Sci. USA 87: 5387-5391.

Bodeau, J.P. and Walbot, V. 1996. Structure and regulation of the maize Bronze2 promoter. Plant Mol. Biol. 32: 599-609.

Brinkmann, U., Martes, R.E. and Buckel, P. 1989. High-level expression of recombinant genes in Escherichia coli is dependent on the availability of the dna $Y$ gene product. Gene 85: 109-114.

Buer, C.S. and Muday, G.K. 2004. The transparent testa4 mutation prevents flavonoid synthesis and alters auxin transport and the response of Arabidopsis roots to gravity and light. Plant Cell 16: 1191-1205.

Chappell, J. and Hahlbrock, K. 1984. Transcription of plant defense genes in response to UV light or fungal elicitor. Nature 311: 76-78.

Christie, J.M. and Jenkins, G.I. 1996. Distinct UV-B and UV-A/blue light signal transduction pathways induce chalcone synthase gene expression in Arabidopsis cells. Plant Cell 8: 1555-1567.

Dangl, J.L., Hauffe, K.-D., Lipphardt, S., Hahlbrock, K. and Scheel, D. 1987. Parsley protoplasts retain differential responsiveness to UV light and fungal elicitor. EMBO J. 6: 2551-2556.

Douglas, C., Hoffmann, H., Schulz, W. and Hahlbrock, K. 1987. Structure and elicitor or U.V.-light-stimulated expression of two 4-coumarate:CoA ligase genes in parsley. EMBO J. 6: 1189-1195.

Dröge-Laser, W., Kaiser, A., Lindsay, W.P., Halkier, B.A., Loake, G.J., Doerner, P., Dixon, R.A. and Lamb, C. 1997. Rapid stimulation of a soybean protein-serine kinase that phosphorylates a novel bZIP DNA-binding protein, G/ HBF-1, during the induction of early transcription-dependent defenses. EMBO J. 16: 726-738.

Faktor, O., Kooter, J.M., Loake, G.J., Dixon, R.A. and Lamb, C.J. 1997a. Differential utilization of regulatory cis-elements for stress-induced and tissue-specific activity of a French bean chalcone synthase promoter. Plant Sci. 124: 175-182.

Faktor, O., Loake, G., Dixon, R.A. and Lamb, C.J. 1997b. The G-box and H-box in a $39 \mathrm{bp}$ region of a French bean chalcone synthase promoter constitute a tissue-specific regulatory element. Plant J. 11: 1105-1113.

Feinbaum, R.L. and Ausubel, F.M. 1988. Transcriptional regulation of the Arabidopsis thaliana chalcone synthase gene. Mol. Cell. Biol. 8: 1985-1992.

Feinbaum, R.L., Storz, G. and Ausubel, F.M. 1991. High intesity and blue light regulated expression of chimeric chalcone synthase genes in transgenic Arabidopsis thaliana plants. Molecular General Genetics 226: 449-456.

Feldbrügge, M., Sprenger, M., Dinkelbach, M., Yazaki, K., Harter, K. and Weisshaar, B. 1994. Functional analysis of a light-responsive plant bZIP transcriptional regulator. Plant Cell 6: 1607-1621.

Feldbrügge, M., Sprenger, M., Hahlbrock, K. and Weisshaar, B. 1997. PcMYB1, a novel plant protein containing a 
DNA-binding domain with one MYB repeat, interacts in vivo with a light-regulatory promoter unit. Plant J. 11: 1079-1093.

Forkmann, G. and Martens, S. 2001. Metabolic engineering and applications of flavonoids. Curr. Opin. Biotech. 12: 155-160.

Foster, R., Izawa, T. and Chua, N.-H. 1994. Plant bZIP proteins gather at ACGT elements. FASEB J. 8: 192-200.

Frohman, M.A., Dush, M.K. and Martin, G.R. 1988. Rapid production of full-length cDNAs from rare transcripts: Amplification using a single gene-specific oligonucleotide primer. Proc. Natl. Acad. Sci. USA 85: 8998-9002.

Green, P.J., Kay, S.A. and Chua, N.-H. 1987. Sequence-specific interactions of a pea nuclear factor with light-responsive elements upstream of the rbcS-3A gene. EMBO J. 6: 2543-2549.

Grotewold, E., Drummond, B.J., Bowen, B. and Peterson, T. 1994. The $m y b$-homologous $\mathrm{P}$ gene controls phlobaphene pigmentation in maize floral organs by directly activating a flavonoid biosynthetic gene subset. Cell 76: 543-553.

Hahlbrock, K. and Ragg, H. 1975. Light-induced changes of enzyme activities in parsley cell suspension cultures. Effects of inhibitors of RNA and protein synthesis. Arch. Biochem. Biophys. 166: 41-46.

Hartmann, U., Valentine, W.J., Christie, J.M., Hays, J., Jenkins, G.I. and Weisshaar, B. 1998. Identification of UV/ blue light-response elements in the Arabidopsis thaliana chalcone synthase promoter using a homologous protoplast transient expression system. Plant Mol. Biol. 36: 741-754.

Heim, M.A., Jakoby, M., Werber, M., Martin, C., Weisshaar, B. and Bailey, P.C. 2003. The basic helix-loop-helix transcription factor family in plants: a genome-wide study of protein structure and functional diversity. Mol. Biol. Evol. 20: 735-747.

Holton, T.A. and Cornish, E.C. 1995. Genetics and Biochemistry of Anthocyanin Biosynthesis. Plant Cell 7: 1071-1083.

Izawa, T., Foster, R. and Chua, N.H. 1993. Plant bZIP protein DNA binding specificity. J. Mol. Biol. 230: 1131-1144.

Jackson, D., Roberts, K. and Martin, C. 1992. Temporal and spatial control of expression of anthocyanin biosynthetic genes in developing flowers of Antirrhinum majus. Plant J. 2: 425-434.

Jin, H., Cominelli, E., Bailey, P., Parr, A., Mehrtens, F., Jones, J., Tonelli, C., Weisshaar, B. and Martin, C. 2000. Transcriptional repression by AtMYB4 controls production of UV-protecting sunscreens in Arabidopsis. EMBO J. 19: 6150-6161.

Kaiser, T., Emmler, K., Kretsch, T., Weisshaar, B., Schäfer, E. and Batschauer, A. 1995. Promoter elements of the mustard CHS1 gene sufficient for light regulation in transgenic plants. Plant Mol. Biol. 28: 219-229.

Kawalleck, P., Somssich, I.E., Feldbrügge, M., Hahlbrock, K. and Weisshaar, B. 1993. Polyubiquitin gene expression and structural properties of the ubi4-2 gene in Petroselinum crispum. Plant Mol. Biol. 21: 673-684.

Koch, M.A., Weisshaar, B., Kroymann, J., Haubold, B. and Mitchell-Olds, T. 2001. Comparative genomics and regulatory evolution: conservation and function of the Chs and Apetala3 promoters. Mol. Biol. Evol. 18: 1882-1891.

Koornneef, M., Luiten, W., de Vlaming, P. and Schram, A.W. 1982. A gene controling flavonoid $3^{\prime}$-hydroxylation in Arabidopsis. Arab. Inf. Serv. 19: 113-115.

Kubasek, W.L., Shirley, B.W., McKillop, A., Goodman, H.M., Briggs, W. and Ausubel, F.M. 1992. Regulation of flavonoid biosynthetic genes in germinating Arabidopsis seedlings. Plant Cell 4: 1229-1236.

Li, J., Ou-Lee, T.-M., Raba, R., Amundson, R.G. and Last, R.L. 1993. Arabidopsis flavonoid mutants are hypersensitive to UV-B irradiation. Plant Cell 5: 171-179.

Martin, C., Prescott, A., Mackay, S., Bartlett, J. and Vrijlandt, E. 1991. Control of anthocyanin biosynthesis in flowers of Antirrhinum majus. Plant J. 1: 37-49.

Menkens, A.E., Schindler, U. and Cashmore, A.R. 1995. The G-box: a ubiquitous regulatory DNA element in plants bound by the GBF family of bZIP proteins. Trends Biochem. Sci. 20: 506-510.

Mol, J., Grotewold, E. and Koes, R. 1998. How genes paint flowers and seeds. Trends Plant Sci. 3: 212-217.

Mol, J., Jenkins, G.I., Schäfer, E. and Weiss, D. 1996. Signal perception, transduction, and gene expression involved in anthocyanin biosynthesis. Critical Rev. Plant Sci. 15: 525-557.

Moyano, E., Martinez-Garcia, J.F. and Martin, C. 1996. Apparent redundancy in $m y b$ gene function provides gearing for the control of flavonoid biosynthesis in Antirrhinum flowers. Plant Cell 8: 1519-1532.

Murphy, A., Peer, W.A. and Taiz, L. 2000. Regulation of auxin transport by aminopeptidases and endogenous flavonoids. Planta 211: 315-324.

Nesi, N., Debeaujon, I., Jond, C., Pelletier, G., Caboche, M. and Lepiniec, L. 2000. The TT8 gene encodes a basic helixloop-helix domain protein required for expression of DFR and BAN genes in Arabidopsis siliques. Plant Cell 12: 1863-1878.

Nesi, N., Jond, C., Debeaujon, I., Caboche, M. and Lepiniec, L. 2001. The Arabidopsis TT2 gene encodes an R2R3 MYB domain protein that acts as a key determinant for proanthocyanidin accumulation in developing seed. Plant Cell 13: 2099-2114.

Peer, W.A., Bandyopadhyay, A., Blakeslee, J.J., Makam, S.N., Chen, R.J., Masson, P.H. and Murphy, A.S. 2004. Variation in expression and protein localization of the PIN family of auxin efflux facilitator proteins in flavonoid mutants with altered auxin transport in Arabidopsis thaliana. Plant Cell 16: 1898-1911.

Peer, W.A., Brown, D.E., Tague, B.W., Muday, G.K., Taiz, L. and Murphy, A.S. 2001. Flavonoid Accumulation Patterns of Transparent Testa Mutants of Arabidopsis. Plant Physiol. 126: 536-548.

Pelletier, M.K., Murrell, J.R. and Shirley, B.W. 1997. Characterization of flavonol synthase and leucoanthocyanidin dioxygenase genes in Arabidopsis. Plant Physiol. 113: 1437-1445.

Pelletier, M.K. and Shirley, B.W. 1996. Analysis of flavanone 3-hydroxylase in Arabidopsis seedlings. Coordinate regulation with chalcone synthase and chalcone isomerase. Plant Physiol. 111: 339-345.

Procissi, A., Dolfini, S., Ronchi, A. and Tonelli, C. 1997. Light-dependent spatial and temporal expression of pigment regulatory genes in developing maize seeds. Plant Cell 9: $1547-1557$

Rabinowicz, P., Braun, E., Wolfe, A., Bowen, B. and Grotewold, E. 1999. Maize R2R3 $M y b$ genes: Sequence analysis reveals amplification in the higher plants. Genetics 153: 427-444.

Romero, I., Fuertes, A., Benito, M.J., Malpical, J.M., Leyva, A. and Paz-Ares, J. 1998. More than 80 R2R3-MYB regulatory genes in the genome of Arabidopsis thaliana. Plant J. 14: 273-284. 
Sainz, M.B., Grotewold, E. and Chandler, V.L. 1997. Evidence for direct activation of an anthocyanin promoter by the maize $\mathrm{C} 1$ protein and comparison of DNA binding by related Myb domain proteins. Plant Cell 9: 611-625.

Sambrook, J., Fritsch, E.F. and Maniatis, T. 1989. Molecular Cloning: A Laboratory Manual. Cold Spring Harbor Laboratory Press, New York, NY.

Sarkar, G. and Sommer, S.S. 1990. The "megaprimer" method of site-directed mutagenesis. BioTechniques 8: 404-407.

Schindler, U., Beckmann, H. and Cashmore, A.R. 1992. TGA1 and G-box binding factors: Two distinct classes of Arabidopsis leucine zipper proteins compete for the G-box-like element TGACGTGG. Plant Cell 4: 1309-1319.

Schoenbohm, C., Martens, S., Eder, C., Forkmann, G. and Weisshaar, B. 2000. Identification of the Arabidopsis thaliana flavonoid 3'-hydroxylase gene and functional expression of the encoded P450 enzyme. Biol. Chem. 381: 749-753.

Schulze-Lefert, P., Dangl, J.L., Becker-André, M., Hahlbrock, K. and Schulz, W. 1989. Inducible in vivo DNA footprints define sequences necessary for UV light activation of the parsley chalcone synthase gene. EMBO J. 8: 651-656.

Shirley, B.W. 1996. Flavonoid biosynthesis: 'new' functions for an 'old' pathway. Trends Plant Sci. 1: 377-382.

Shirley, B.W., Hanley, S. and Goodman, H.M. 1992. Effects of ionizing radiation on a plant genome: analysis of two Arabidopsis transparent testa mutations. Plant Cell 4: 333-347.

Shirley, B.W., Kubasek, W.L., Storz, G., Bruggemann, E., Koornneef, M., Ausubel, F.M. and Goodman, H.M. 1995. Analysis of Arabidopsis mutants deficient in flavonoid biosynthesis. Plant J. 8: 659-671.
Sprenger-Haussels, M. and Weisshaar, B. 2000. Transactivation properties of parsley proline rich bZIP transcription factors. Plant J. 22: 1-8.

Stracke, R., Werber, M. and Weisshaar, B. 2001. The R2R3-MYB gene family in Arabidopsis thaliana. Curr. Opin. Plant Biol. 4: 447-456.

Trezzini, G.F., Horrichs, A. and Somssich, I.E. 1993. Isolation of putative defense-related genes from Arabidopsis thaliana and expression in fungal elicitor-treated cells. Plant Mol. Biol. 21: 385-389.

Weisshaar, B., Armstrong, G.A., Block, A., da Costa e Silva, O. and Hahlbrock, K. 1991. Light-inducible and constitutively expressed DNA-binding proteins recognizing a plant promoter element with functional relevance in light responsiveness. EMBO J. 10: 1777-1786.

Weisshaar, B. and Jenkins, G.I. 1998. Phenylpropanoid biosynthesis and its regulation. Curr. Opin. Plant Biol. 1: 251-257.

Williams, M.E., Foster, R. and Chua, N.-H. 1992. Sequences flanking the hexameric G-box core CACGTG affect the specificity of protein binding. Plant Cell 4: 485-496.

Winkel-Shirley, B. 2001. Flavonoid biosynthesis. A colorful model for Genetics, Biochemistry, Cell Biology, and Biotechnology. Plant Physiol. 126: 485-493.

Wisman, E., Hartmann, U., Sagasser, M., Baumann, E., Palme, K., Hahlbrock, K., Saedler, H. and Weisshaar, B. 1998. Knock-out mutants from an En-1 mutagenized Arabidopsis thaliana population generate new phenylpropanoid biosynthesis phenotypes. Proc. Natl. Acad. Sci. USA 95: 12432 12437. 